\title{
Philosophy of Technical Equipment Improvement as Exemplified by a Jaw Crusher
}

\author{
Aleksey Sergeevich Vasilev*, Ilya Romanovich Shegelman, Vladimir Nigmatovich Aminov, Elena \\ Evgenevna Kameneva and Pavel Olegovich Shchukin
}

Petrozavodsk State University, av. Lenina, 33, Petrozavodsk, 185000, The Republic of Karelia, Russia; alvas@petrsu.ru; shegelman@onego.ru; v.aminov@mail.ru; elena.kameneva@mail.ru; pavelpsu@mail.ru

\begin{abstract}
Objectives: Current importance of the investigation has been stipulated by the necessity to solve the tasks set before domestic mechanical engineering to develop new energy efficient equipment and energy saving technologies. Methods: The study demonstrates the possibility for the synthesis of innovative technical and technological solutions by developing the intellectual arrays of object development as exemplified by a jaw crusher. The method of the study is represented by the construction of the intellectual array of technological object development based on the comprehensive studies of scientific, technical, popular science literature and patent files. Findings: A number of innovative technical solutions have been developed; the relevant patent applications have been submitted to the authorized bodies. It has been shown that the philosophy of technological equipment improvement founded on the creation of the intellectual arrays of its development represents a powerful tool for establishing the level of development of a technological object and for the synthesis of patentable innovative solutions. Applications/Improvements: The possibility of the synthesis of patentable solutions has been proven based on the analysis of the existing similar designs and their prospective structural and technological development.
\end{abstract}

Keywords: Innovations, Intellectual Array, Jaw Crusher, Philosophy of Technology

\section{Introduction}

One of the most important problems faced by domestic technical engineering is represented by the creation of the modern energy efficient equipment and by the development of energy saving technologies. This objective makes for the continuous search for new technical and technological solutions whose success is largely predetermined by the capability to abstract from the typical and conventional solutions. This exercise would require applying either creative or philosophical approaches, i.e. considering the object of technology from the perspectives of some special philosophical discipline called Philosophy of technology which is called upon to illuminate the hidden principle of the whole world of technology in its phenomenal manifestation. The attention here is focused on the essential, latent principles, on the nature of technological phenomena $a^{1}$." The experience of the authors of this study in the area of innovative activities proves that the most efficient way to search for the methods of development of the objects of technology is represented by considering it not from scientific and technical perspectives only, but also by considering it within the framework of Philosophy of technology. When an object of technology is considered from scientific and technical perspectives it mostly helps discover the evolutional ways for its improvement and thus makes it possible to ensure just a slight upgrade of the already known device. However, when, in addition to the abovementioned scientific and technical approaches, another creative approach is applied then considering the technological object from the perspectives of philosophy of technology makes it possible to obtain a much broader and comprehensive view of the problem under consideration which facilitates synthesizing the new breakthrough

${ }^{*}$ Author for correspondence 
technical solutions and bringing this object of technology to the new much more higher level creating the technologies of the new generation.

Consider the application of this approach exemplified by the resolution of the problem of improving the energy efficiency of the process of crushing the large size rocks. One of the possible options for solving this issue is to create the energy efficient design of a jaw crusher that would ensure the production of high quality cubiform crushed stone. This example is founded on the authors' personal experience obtained in the course of their work on the complex project called "Investigation of the processes of hard rock disintegration to reduce energy consumption and to increase the output in the process of treatment and enrichment of natural ore and technogenic materials" implemented by Petrozavodsk State University within the framework of the Federal Special Program "Investigations and research studies on the priority area of scientific and technological complex development for 2014-2020" under the agreement dd. 10.20.2014 No. 14.574.21.0108. Actual importance of this work has been confirmed by the golden medal and diploma awarded, following the results of the $74^{\text {th }}$ International Technological Fair in 2015 (28.09 - 03.10.2015, Plovdiv, Bulgaria) for the exhibit item called "Methods of disintegration and the equipment for improving the efficiency of reprocessing construction rocks".

In the course of the development of this work over 200 domestic and foreign patents have been selected and analyzed, more than 100 sources of scientific and technical information have been studied and analyzed in detail in a specifically dedicated report ${ }^{2}$. The authors have analyzed not only the materials related to structural and technological solutions $s^{3.4}$, but also the methods of evaluation of jaw crusher energy efficiency, 5,6 the influence of rock strength properties on jaw crusher performance ${ }^{7,8}$, the ways and methods that not only help calculate the structural strength, but also facilitate forecasting the reliability and wear rate ${ }^{9,10}$.

\section{Concept Headings}

Development of the new and the improvement of the existing equipment necessitate the resolution of a number of problems, including the tasks listed below:

1. Establish the technical level and trends of the development of the structures of the technological object under consideration;
2. Create the intellectual arrays of the technological object development;

3. Synthesize the technical solutions aimed at the improvement of the existing structures of the technological object and create the structures of the new generation; and

4. Patent the suggested technical solutions.

The object of technology in this case is represented by a jaw crusher.

To solve the first problem of the establishment of the technical level and trends of jaw crusher development a special patent and information research study was under taken in the course of which both domestic and foreign patent-related documents, scientific and technical literature $e^{2}$, presentation materials $\frac{11,12}{}$, booklets $\frac{13,14}{14}$ and catalogues of the world jaw crusher manufacturers $\frac{15-18}{}$ have been analyzed profoundly. The patent search among the right protecting documents (inventions, utility models, inventor's certificates) in the Russian Federation was undertaken in the databases of the Federal Institute of Industrial Property (FIPS) that establishes the State Patent Fund and represents the central archive of SPF. The patent search among the right protecting documents of foreign countries was carried out using the patent information databases of European Patent Office, esp@cenet, patentscope. The procedures of the patent search were in full conformity with GOST 15.011. The depth of the patent search starting from the most recent among the selected patents amounted to 67 years. The information search was undertaken among the scientific articles published in periodical and non-periodical press, among the materials of the conferences, among scientific and technical literary sources, booklets and catalogues of the companies, among the published summaries of the theses and in the doctoral dissertations directly. Among the information databases the authors would like to note the database of the scientific electronic libraryelibrary.ru, the database of All-Russian Institute for Scientific and Technical Information of Russian Academy of Science (VINITI RAN), sciencedirect.com, etc.

Solving the second problem associated with the construction of the intellectual array of jaw crusher development the authors made use of the theory of functional and technological analysis and synthesis of the patentable objects of technology. Thereat, the object of the investigation was represented by the jaw crusher designed for crushing hard rocks to obtain cubiform crushed stone; 
and the technological system was represented by the system "jaw crusher-rocks". The detailed consideration of the specified technological system in general, of its separate elements and of the interrelations between them made it possible to build two intellectual arrays of the investigated object development, namely, the intellectual array of the technical solutions for the development of the jaw crushers (Figure 1) and the intellectual array of structural solution development (Figure 2).

The development matrices or arrays are called "intellectual", because they are founded on the information collected from the documents that reflect the results of the intellectual activity (patents, scientific articles, etc.).

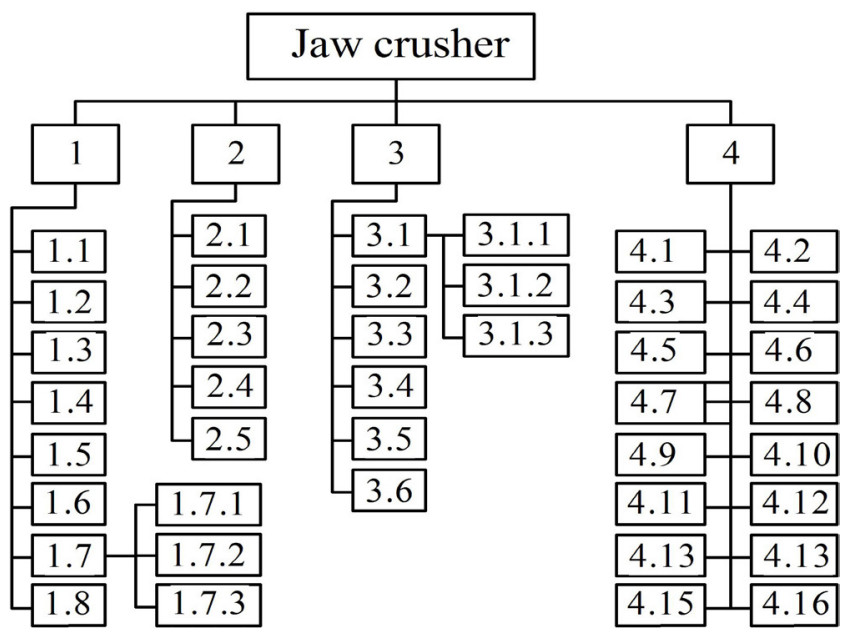

Figure 1. Intellectual array of technical solution development.

Figure 1applies the legend as follows:

1 - Performance improvement; 1.1 - crushing chamber improvement; 1.2 - work tool improvement (jaws); 1.3 drive design improvement; 1.4 - improved conditions for discharging the crushed product from the output slot of the crusher; 1.5 - ensuring continuous feed of raw materials to the crusher (cave-in operation); 1.6 - improved coefficient of filling the crushing chamber with the materials to be crushed; 1.7 -shorter shutdown periods; 1.7.1 - decreased number of failures; 1.7.2 - longer period in between maintenance; 1.7.3 - eliminating the need to remove the uncrushed materials from the crushing chamber when the crusher has to be put in cave-in operation; 1.8 - increased intensity of the interaction between the lumps of the crushed material and the operating tools and between the lumps proper; 2 - improved reliability; 2.1 improved strength and reliability of the structural units; 2.2 - improved protection of the operating tools from the damages caused by the crush-resistant bodies; 2.3 streamlining of the structure; 2.4 - reducing the effects of vibrations on the elements of the drive, on the base, on the structural elements; 2.5 - reducing the force transmitted onto the supporting frame; 3 - drive improvement; 3.1 - reliability improvement; 3.1.1 - improved reliability of the fixtures between the elements of the drive and the base; 3.1.2 - improved reliability of the control devices; 3.1.3 - improved reliability of the structural elements of the drive; 3.2 - ensuring the possibility to put the crusher in operation under in-cave conditions; 3.3 - structural streamlining; 3.4 - employing the movable jaw complex trajectory; 3.5 - eliminating the backward (idle) run of the jaw; 3.6 - ensuring the continuous kinematics of the structure; 4 - improved technological parameters; 4.1 controlling the sizes of the resulting crushed product by means of the output slot size control; 4.2 - lower labor intensity during maintenance, repairs and revamps; 4.3 carrying out maintenance without the need to remove the crushed material from the crushing chamber; 4.4 - lower ratio of the bottom fraction of the material; 4.5 - eliminating the unequal wear of the operating surface of the corrugated jaws; 4.6 - providing the possibility for preliminary crushing of the clogging lumps of the crushed material; 4.7 - optimization of the dependency of crusher performance indicators on the frequency and strokes of the movable jaw; 4.8 - improved efficiency coefficient; 4.9 - improved environmental safety; 4.10 - lower specific energy consumption rate; 4.11 - improved economical efficiency of crushing; 4.12 - product ripping in the crushing chamber to prevent the output slot clogging; 4.13 - forced pushing of the material in the operational crushing area; 4.14 - ensuring the operability of the crusher in cases when the crush-resistant body gets inside and when the dimensions of this body are larger than the discharge slot; 4.15 - improved resistance against attrition of the operating tools; 4.16 - improved structural resistance against vibrations.

Intellectual array of the jaw crusher development (Figure 2) includes the elements as follows: $\mathrm{C}$ - crushing chamber, C.1 - geometrical dimensions, C.1.1 - dimensions of the input opening, C.1.2 - output slot control, C.1.3 - crushing chamber taper, C.1.4 - crushing chamber compression stroke, C.1.5 - crushing chamber geometrical shape, C.1.6 - crushing chamber volume, C.1.6.1 - crushing chamber height, C.1.6.2 - crushing chamber width, C.2 - number of crushing chambers, 



Figure 2. Intellectual array of structural solution development.

C.2.1 - single chamber type, C.2.1.1 - one movable jaw, one fixed jaw, C.2.1.2 - two movable jaws, C.2.2 - double chamber type, C.2.2.1 - two fixed jaws, one movable jaw, C.2.2.2 - two fixed jaws, two movable jaws, C.3 - crushing zones, C.3.1 - not divided in zones, C.3.2 - divided in zones, C.3.2.1 - different geometry of corrugation of the operating surfaces of the jaws at different levels of the crushing chamber, C.3.2.2 - compound jaw (made of the pivot fixed plates), C.3.2.3 - on the jaws at different levels of the crushing chamber the operating elements with different geometry are installed, C.3.2.4 - operating elements of the jaws that are equipped with individual drives at different levels of the crushing chamber that move with different intensity, J - jaw structure, J.1- jaw geometry, J.1.1 - rectangular, J.1.2 - trapezoidal, J.2 - material of the jaws and its thermal treatment, J.3 - fixtures between the jaws and the base, J.4 - jaw lining, J.4.1 - material of the lining and its thermal treatment, J.4.2 - lining geometry, J.4.2.1 - vertical location of ribs, J.4.2.2 - horizontal location of ribs, J.4.2.3 - slanted location of ribs, J.4.2.4 - combined location of ribs, J.5 - installation of additional elements (operating tools) on the jaws, J.5.1 - place of installation of operating tools on the jaw, J.5.1.1 - installation directly on the jaw, J.5.1.2 - installa- tion of the plates with operational tools, J.5.2 - operating tool fixation method, J.5.2.1 - fixed, J.5.2.1.1 - weld-up, J.5.2.1.2 - welding, J.5.2.1.3 - monolith (manufactured with the plate as one piece), J.5.2.2 - removable, J.5.2.2.1 have one operational facet (replaced when worn out), J.5.2.2.2 - have several operational facets (when one facet is worn out the part is reinstalled to operate with another facet), J.5.3 - possibility to sharpen the operating tools, J.5.3.1 - no possibility to sharpen for one more time, J.5.3.2 - possibility to sharpen with consequent reuse, J.5.3.3 - requiring reinstallation when worn out (have several operating edges), J.5.4 - drive of the operating tools, J.5.4.1 - no individual (additional) drive, J.5.4.2 - with group drive of the operating tools, J.5.4.3 - with individual drive for each operating tool, J.5.5 - material of the operating tools and its thermal treatment, J.6 - openings in the jaw, J.7 - jaw design (jaw integrity), J.7.1 - monolith jaw, J.7.2 - compound jaw, D - crusher drive, D.1 - movable jaw drive, D.1.1 - transmission mechanism of the movable jaw drive, D.1.1.1 - mechanical, D.1.1.2 - lever, D.1.1.3 - cam, D.1.2 - hydraulic, D.2 - operating tool drive, D.2.1 - no individual drive (moves together with the jaw), D.2.2 - additional vibration drive, D.2.2.1 - continuous, D.2.2.2 - discontinuous operation.

Inasmuch as the analysis of the selected scientific, technical and patent documents shows that most technical solutions are aimed at achieving several objectives simultaneously, for example, improving the workability and the economics of the installation or improving the wear resistance and the operational life of the crushing plate of the jaw crusher, reducing the probability of the unexpected failure, improving operability in the course of casting and thermal treatment, ensuring high efficiency of crushing the rocks applying minimal forces to achieve



Figure 3. "Tree of objectives" for jaw crusher improvement. 
the required rate of crushing; improving the service life, in order to create the array of development, the decision was made that the object under investigation should be classified based on its structural attributes only, i.e. the technological result that is achieved by means of that or another structural change has not been reflected in this option of the array. For this purpose the "tree of objectives" was developed (Figure 3).

Figure 3 applies the legend as follows: CQ - crushed product quality improvement; EE - energy efficiency improvement; E - efficiency improvement; MS - maintenance streamlining; MA - maintenance ability improvement; $\mathrm{W}$ - plant weight reduction; OD - overall dimensions reduction; $\mathrm{R}$ - reliability improvement; SW - structural workability improvement; SL - service life increase; $\mathrm{C}$ - crushing rate control; $\mathrm{M}$ - materials consumption reduction; $\mathrm{S}$ - structural streamlining.

For instance, one of the ways to improve the reliability of the crushers is to implement measures against the resonance and against the detrimental consequences of vibrations that occur in the course of the operation of the crusher and that result in the short operational life of the bearings, of the parts of the fixing units and of the controlling devices of the plant. In order to reduce these detrimental vibration loads on the supporting platform and on the structural elements, the dynamic balancing is usually implemented. The complexity of the balance adjustment is associated with the fact that the center of gravity of the movable crushing jaw is moving along the elliptical trajectory, while the center of gravity of the counterbalance that is installed on the flywheel pulley follows the circular trajectory. To solve this problem, Metso, the world's leading manufacturer of the equipment for mining industry suggests the designs of the jaw crushers equipped with the weldless module frame that ensure their high fatigue strength and good reliability ${ }^{19}$.

Combined application of several approaches (scientific, technical and the philosophy of technology) made it possible to unconventionally consider the problem of the search for the ways to improve the technological object; as a result, the "tree of objectives" and two intellectual arrays have been developed one of which reflects the technological areas while another one represents the technical areas of development. Such multifaceted analysis helped establish the technical level of the technological object development and also identify the areas for further improvements from both structural and technological perspectives. The above made it possible to proceed with the solution of the third task on the synthesis of the technical solutions aimed at the improvement of the jaw crusher design. Based on the combined analysis of the intellectual arrays of the jaw crusher development and upon applying the "tree of objectives" the authors of this study managed to find a number of technical solutions for improving the design of the jaw crushers and for improving the process of crushing the lump rocks with this type of equipment.

At the fourth stage of the investigation based on the developed technical solutions the patent applications for inventions and utility models have been duly prepared and submitted to FIPS.

\section{Results}

Among the developed new solutions one particular solution has to be noted as it is aimed at the intensification of the process of crushing the lump materials, at reducing the plant downtimes caused by the necessity to clean the crushing chambers because the output slot might get clogged with the crushed products. The positive effect is achieved due to the following measures: within the jaw crusher that consists of the housing with chamber for the passage of the crushed material of standard fraction, the fixed jaw and the movable jaw that is connected to the drive and features the evenly distributed perforations on the rear side of the movable jaw (cell D.2.7.2, Figure 2), at least one spring loaded plate should be installed in parallel and should be equipped with the pins that go through the openings in the fixed plate (cell D.2.6, Figure 2); thereat, the spring loaded plate should be equipped with the impact drive (cell D.3.2.2, Figure 2), and in the housing of the unit an additional chamber should be installed for the passage of the fine substandard fractions of the crushed material that have passed through the openings in the movable jaw. This technical solution has been granted patent RU 157535 "Jaw crusher". Thus, in this case the improvements simultaneously follow several branches of the intellectual array of development: first, there is a change in the design of the jaw (branch J of the intellectual array of development), second, there is a change to the drive (branch $\mathrm{C}$ of the intellectual array of development), namely, the installation of an additional vibration discontinuous action drive for the spring loaded plate.

In the course of the operations with the intellectual array of development several new methods have been suggested for crushing the lump rocks with the jaw crusher (including patent application RU 2016108474 
"The method of crushing lump rocks with jaw crusher") together with the devices for their implementation focused on the improvement of crushing efficiency and on the reduction of the required compression forces for crushing. The basic principle of these methods is that to achieve the abovementioned objectives, the rocks that are under stressed conditions should be affected by the additional destructive impulse-impact force during the moment when the rocks are pressed between the jaws in the course of the operational stroke of the movable jaw. To reduce the energy consumption rate, the additional drive of the impact device does not have to operate continuously; it has to be switched on intermittently for a short time in automated mode when the impact element interacts with the lumps of rock that are pressed between the jaws and it should be switched off when there are no rocks (cell D.2.2.2, Figure 2).

This method of crushing can be implemented within the structure of the jaw crusher that consists of the housing with the fixed jaw, of the movable jaw with the lower oscillation axis and of the oscillation drive installed in the upper section of the housing. It is suggested that on the rear side of the fixed jaw in parallel to it a plate should be installed with the pins that come through the openings in the fixed jaw. Thereat, each of the pins should be equipped with its own individual drive that would ensure its impulse-impact movement. The drive is to be switched on when the pin interacts with the lump of rock that is pressed between the jaws; and it is to be switched off when there is no rock.

The major difference of the method (patent application RU 2016108474 "The method of crushing lump rocks with jaw crusher" is represented by the fact that the crushing chamber is divided in zones over the height of the chamber (cell C.3.2, Figure 2). In each of the designated zones the compressed lumps of the rocks are additionally affected with the vibration impacts of individual parameters (cell C.3.2.4, Figure 2). Due to this fact depending on the sizes of the crushed lumps of rocks that are located in that or another zone it is possible to preset the optimal parameters of the crushing process to destroy the lumps of the rocks of the specific fraction that is presently located in any specific zone of the crushing chamber.

The method of crushing lump rocks can be implemented within the structure of the jaw crusher that consists of the housing with the fixed jaw, of the movable jaw with the lower oscillation axis and of the oscillation drive installed in the upper part of the housing. At the operating side of the fixed jaw in parallel to it the plates displaced across the height and equipped with the operating elements are installed; each of these plates is spring loaded with pressure springs relative to the fixed jaw and is equipped with an individual drive that ensures its vibration stroke; thereat, the drive is switched on and off automatically depending on the position of the spring loaded plate relative to the fixed jaw.

\section{Discussion}

Studying the object of technology from scientific and structural perspectives simultaneously applying philosophical analysis proves to be a promising method of searching for new technical solutions for its further improvement. Viewing the object from the perspectives of philosophy of technology makes it possible to step over the limitations of design that are predetermined by the technical knowledge of the developer. The construction of the intellectual array of development based on the comprehensive analysis of the patents, scientific and technical literature makes it possible to establish the technical level that has been achieved by the technological object development by the moment of the investigation, to trace the history and the trends of development of the technological object and to suggest the new directions for its improvement. Thereat, the collected information is systematized and presented as the intellectual array where each cell corresponds to some certain technical solution. All technical solutions, reflected in the intellectual array of development are classified according to some definite attributes. Later, the obtained intellectual array is supplemented with new cells that reflect the possible ways of development of the object of technology. And then, assisted by the experts in different areas of science and by the industrial specialists, the technical opportunities for their practical implementation should be investigated. This methodology has been applied successfully by the authors of this study in their search for the new innovative patentable technical solutions and its results have been described in several scientific studies ${ }^{19-23}$ and also in a great number of patents that the authors were fortunate enough to be granted in different industries. Application of this methodology is efficient when the industrial companies that employ great number of the experts who posses vast practical experience combine their efforts with the investigations of the scientists including those from the higher educational institutions who possess 
a wealth of theoretical knowledge. With this approach theoretical and practical knowledge can be combined in quite a successful manner thus facilitating the synthesis of innovative technical solutions that make their great contribution to the development of the technological object under consideration.

\section{Conclusion}

In the course of the development of this study over 200 domestic and foreign patents have been selected and analyzed; more than 100 sources of scientific and technical information havebeen studied and taken as the foundations for the creation of the intellectual array of development of the jaw crusher and for the construction of the "tree of objectives". Thanks to the detailed investigations that were undertaken for the object under consideration and that interpreted this object not only from the perspectives of science and technology but also from the perspectives of philosophy of technology, it proved possible to solve the complex problem of the improvement of the complicated design of the technological object which in this case was represented by the jaw crusher, to split the problem into a number of simpler tasks of improving some particular units and parts and of ensuring their interaction with each other. The application of the conventional scientific and technological vision implies the development of technical solutions with simultaneous analysis of the opportunities for their implementation that are based on the "designer" knowledge of the investigator. Thereat, the application of the approaches of philosophy of technology, and in this particular case the application of the intellectual arrays of development makes it possible to abstract from the typical solutions and to suggest the new areas for improvements without thinking too much at this stage of how these things should be implemented in practice. Upon the development of new solutions or new areas of improvement there follows the search for the opportunities for their implementation, that is supposed to engage the wide circles of scientists, experts in different area, i.e. not only designers, but also technologists, material scientists, engineers and technicians, etc.

While synthesizing the new technical solutions it is very convenient to describe the object as the intellectual array of development; thereat, the number of arrays and their contents depend on the complexity of the object under consideration and on the essence of the selected objective.
Upon the construction of the intellectual array of the technological object development based on the analysis of the existing designs and known technical solutions this array is supplemented with the new potential areas of development; thereat, the object of technology is to be regarded from the perspectives of philosophy of technology, i.e. from the perspectives of the technical world constitution, not from the positions of technical science.

Construction of the intellectual array of the technological object development makes it possible to trace and then to forecast the potential trends in changes of the elements of the design and their interrelation with each other that in turn enables proceeding with the implementation of the technical solutions through the development of design documents according to the created intellectual array.

Based on the technical solutions that have been synthesized applying the intellectual array of jaw crusher development, several patent applications have been submitted to FIPS; up to now patent have been granted for the utility models RU 157535 "Jaw crusher". Other applications are still studied by FIPS and undergo the relevant expert assessment.

\section{Acknowledgements}

The study has been developed with the support from the Ministry of Education and Science of the Russian Federation under the agreement with Petrozavodsk State University dd. 10.20.2014 No. 14.574.21.0108 according to the Federal Special Program "Investigations and research studies on the priority area of scientific and technological complex development for 2014-2020". Unique identifier of the applied scientific investigation (project): RFMEFI57414X0108.

\section{References}

1. Ivanov BI. Modern Philosophy of Engineering: Problems and Perspectives, Mysl. 2009; 8:194-202.

2. Investigating Technical Level in Design of the Equipment for Disintegration of Rocks (Jaw Crushers): Research Study Report 2014-14-576-0155-009. Petrozavodsk State University. Ed. by I. R. Shegelman. Petrozavodsk; 2015. No.GR 114120370042.

3. DeDiemar RB. New Concepts in Jaw Crusher Technology, Minerals Engineering. 1990; 3(1-2):67-74. ISSN 08926875 . 
4. Gupta A, Yan DS. Chapter 4 - Jaw Crusher, In: Mineral Processing Design and Operation. Edited by A. Gupta, D. S. Yan, Elsevier Science, Amsterdam; 2006. 99-127. ISBN 9780444516367.

5. Legendre D, Zevenhoven R. Assessing the Energy Efficiency of a Jaw Crusher, Energy. 2014 Sep; 74(1):119-30.

6. Refahi A, Aghazadeh Mohandesi J, Rezai B. Comparison between Bond Crushing Energy and Fracture Energy of Rocks in a Jaw Crusher using Numerical Simulation. Journal of the Southern African Institute of Mining and Metallurgy. 2009; 109:709-17.

7. Olaleye BM. Influence of some Rock Strength Properties on Jaw Crusher Performance in Granite Quarry, Mining Science and Technology (China). 2010 Mar; 20(2):204-08. ISSN 1674-5264.

8. Petukhov AN, Markov BF, Zhelobkov PS. New Generation Jaw Crusher. Proceedings of the University, Karaganda State University, 2013, 2, 44-48. ISSN 1609-1825.

9. Refahi A, Aghazadeh Mohandesi J, Rezai B. Discrete Element Modeling for Predicting Breakage Behavior and Fracture Energy of a Single Particle in a Jaw Crusher, International Journal of Mineral Processing, 94. 2010 Feb; 19(1-2):83-91. ISSN 0301-7516.

10. Lindqvist M, Evertsson CM. Liner Wear in Jaw Crushers, Minerals Engineering. 2003 Jan; 16(1):1-12. ISSN 08926875.

11. Onoda T. Introduction of Product. BR 1000JG-1 Mobile Crusher. Date accessed: 09.14.2016. Available at: http:// www.komatsu.com/CompanyInfo/profile/report/pdf/15305_E.pdf.

12. Sundstrom T. A Jaw Crusher Application in the Mining Industry. Technology and Applications, SPM Instrument AB, Aug 2014. Date accessed: 09.17.2016. Available at: http:/www.spminstrument.com/Documents/Downloads/ Sales\%20packages/Mining/CS_012B_JawCrusher_ Boliden_SE.pdf.

13. Jaw crushers. Jaw Breakers. China Jaw Crusher, Jaw Crusher Machine-China Hongxing. Date accessed: 09.16.2016.
Available at: http://www.hxjqchina.com/pro/jaw_crusher. html\#.

14. Jaw Crushers for Stage, Primary Rock Crushing. Date accessed: 09.16. 2016. Available at: http://www.parkerplant.com/crushing-and-screening/crushers/jaws.

15. Jaw Crusher, Jaw Crushers Manufacturers in China (Sanme Sino-German JV Holding). Date accessed: 09.17.2016. Available at: http://www.sanmecrusher.com/products/ crusher/jaw-crusher.html.

16. Jaw Crusher-Henan Bailing Machinery. Date accessed: 09.17.2016. Available at: http://www.bailingmachinery. com/products/crusher/14.html.

17. Sandvik Jaw Crusher, 2012. Date accessed: 09.21.2016. Available at: http://www.miningandconstruction. sandvik.com/__c125715e002 ebf7d.nsf/Alldocs/ $\mathrm{Jaw}^{\star} 2 \mathrm{AJaw}{ }^{\star}$ brochure/\$file/Sandvik\%20Jaw_eng.pdf.

18. Product Finder - Metso. Date accessed: 09.21.2016. Available at: http://www.metso.com/product-finder/\#/ tags=693/Family/All.

19. Product Finder - Metso, Jaw Crusher. Date accessed: 20.06.20.2016. Available at: http://www.metso.com/product-finder?industry=Mining\#/By\%20family/Crushers/ Jaw\%20crushers.

20. Shegelman IR, Romanov AV, Vasiliev AS, Shchukin PO. Scientific and Technical Aspects of Creating Spent Nuclear Fuel Shipping and Storage Equipment, Nuclear Physics and Atomic Energy. 2013; 14(1):33-37.

21. Palani S, Suresh K, Thanesh A, Muthukumar S. Design and Development of Billet Sawing Machine for Improving Productivity, IJST. 2016 Jan; 9(1).

22. Ilayaraja K, Zafar Eqyaabal MD. Value Engineering in Construction, IJST. 2015 Nov; 8(32).

23. Shegelman I, Shchukin P, Vasilev A. Integration of Universities and Industrial Enterprises as a Factor of Higher Vocational Education Development, Procedia Social and Behavioral Sciences. 2015 Dec; 214(5):112-18. Date accessed: 09.22.2016. Available at: http://www.sciencedirect.com/science/article/pii/S187704281505956X. 